\title{
Liberalization of European migration and the immigration of skilled people to Sweden
}

\author{
Olof Ejermo ${ }^{1}$ and Yannu Zheng ${ }^{1,2^{*}}$
}

* Correspondence:
yannu.zheng@ekh.lu.se;
yannu.zheng@icloud.com;
yannu.zheng@gmail.com
${ }^{1}$ Centre for Innovation, Research
and Competence in the Learning
Economy (CIRCLE), Lund University,
Lund, Sweden
2Department of Economic History,
Lund University, Lund, Sweden

* Correspondence: yannu.zheng@ekhlusse; search Lund, Sweden

Lund University, Lund, Sweden

\begin{abstract}
Migration policies can have a strong impact on the selection of immigrants, who in turn can affect the host country's innovation development. This paper examines the effects of the liberalization of migration on the skill composition of immigrants from the EU-15 to Sweden after the inception of the European Economic Area (EEA) in 1994. We examine its effect on immigrants' education levels and probability of becoming an inventor, comparing immigrants from the EU-15 with those from other developed regions in difference-in-differences regressions. The results show that the liberalization of migration had a negative effect on the educational profile of new EU-15 immigrants in the short run, but there is no such effect in the long run. Moreover, the liberalization of migration has no systematic effect on the EU-15 immigrants' probability of becoming an inventor in neither the short nor the long run. These patterns are consistent with the theoretical implication that reduction in migration costs associated with the EEA mainly stimulated migration from the lower end of the education distribution.
\end{abstract}

JEL classification: J15, J24, N30, O31

Keywords: Human capital, Immigration, Innovation, Selection, Skill level

\section{Introduction}

Migration policies can have a strong impact on which immigrants choose to move to another country and their skill levels, whether intended or not (Bianchi 2013). These policies can in turn affect innovation development in the country to which those immigrants move. For example, Kerr and Lincoln (2010) find that higher levels of entry by those holding an $\mathrm{H}-1 \mathrm{~B}$ visa ${ }^{1}$ increase employment among immigrants in science and engineering as well as patenting by inventors with surnames that appeared to be Indian and Chinese. Although some researchers have tried to investigate the impact of changes of migration policy on the composition of skills among immigrants, most of them focus on the impact of specific policy changes and immigrant groups (Chen 2005; Kato and Sparber 2013). Empirical evidence on the impact of more general liberalization of migration policies is still scarce.

One of the biggest changes in migration policy history in Europe is the liberalization of migration through the European Economic Area (EEA) agreement between the 
European Union (EU) and the European Free Trade Association (EFTA) countries in 1994. The agreement, which originally involved 17 countries, has grown in importance with the large expansion of the EU. In short, the EEA allows for the free movement of individuals among its member countries. However, little is known about how the European integration process has affected the skill composition of immigrants in the member countries. One earlier study similar as our study is from Huber and BockSchappelwein (2014), who find that the EEA has a positive impact on the education level of permanent migrants to Austria.

However, it is far from clear that the results in Austria can be generalized to other EEA countries. In particular, we examine the case of Sweden. The similarities between Sweden and Austria are, at first glance, striking. They have a similar population size and proportion of foreign born as well as generous welfare benefits (OECD 2016a, 2016b). ${ }^{2}$ High welfare ambitions in both Austria and Sweden raise rewards to low-skilled workers for migrating to those countries over other countries. However, Austria and Sweden differ, for example, when it comes to the country of origin for immigrants. ${ }^{3}$

The effect of liberalization of migration has a theoretically ambiguous effect in terms of the selection of immigrants at different skill levels. Theory highlights the distribution of skills and rewards to skills in the receiving and sending countries, as well as migration costs that in turn determine the self-selection behavior of migrating individuals under free migration (Borjas 1987; Grogger and Hanson 2011). Our prediction from a theoretical framework based on Grogger and Hanson (2011) is that the average skill level for immigrants to Sweden decrease under free migration.

We examine this issue empirically based on a unique database that links inventors to the general population in Sweden (Jung and Ejermo 2014; Zheng and Ejermo 2015). We examine the effect of the full liberalization of migration on the skill composition of new immigrants in Sweden who originated in the EU-15. ${ }^{4}$ We exclude Denmark and Finland from the treatment group, as they have been part of a free-labor mobility agreement among the Nordic countries since 1954. Sweden's accession to the EEA means that all EU-15 citizens could move to Sweden freely. We use difference-in-differences (DiD) estimations to evaluate the impact of liberalization on the skill composition of immigrants. This method means that the treatment group (i.e., EU-15 citizens) is compared in terms of skill composition (education, probability of becoming an inventor) both against themselves before treatment and relative to the trend in the control groups.

The results of our study indicate that the EEA had short-term negative effects on the selection of immigrants from the EU-15 with respect to their education level. This is manifested as both an increased probability that EU-15 immigrants had a low level of education and a decreased probability that they were highly educated. However, it is also clear that those effects are temporary, as estimated lead and lag models show the effect to be statistically significant only in the first years after the application of liberalization. Moreover, with respect to patenting, we see no systematic effects in our main result of interest after controlling for other variables. Our results are consistent with the theoretical assumption that negative selection driven by reduction in migration costs mainly applies to low-skilled immigrants in the studied case.

The rest of the paper is structured as follows. Section 2 summarizes Swedish migration history. Section 3 reviews previous studies examining the impact of migration policy selection of migrants. Section 4 discusses the theoretical background. Section 5 
presents the database and descriptive statistics. Section 6 describes the methods used. Section 7 reports the results of the empirical analysis. The final section draws conclusion based on the study.

\section{The Swedish migration experience}

Immigration to Sweden started to take off after World War II. In the 1950s and 1960s, high economic growth led to large inflows of immigrants for work reasons, who mainly originated in Nordic and Southern European countries (Bevelander 2000). In 1954, the five Nordic countries (Denmark, Finland, Iceland, Norway, and Sweden) enacted free movement in the entire area (Bevelander 2000; Stalker 2002). This treaty allowed largescale emigration from the other Nordic countries to Sweden and especially Finns emigrated (Westin 2000; Helgertz 2010). However, labor migration from non-Nordic countries came to a halt in the mid-1970s following an economic slowdown, and refugee migration started to dominate immigration flows to Sweden, a trend that continued until recently. ${ }^{5}$ The European integration process started to change this, first with the implementation of the EEA in 1994, a free trade agreement that allows free mobility between the EFTA and the EU member countries, and then with Sweden's membership in the EU along with Finland and Austria in 1995. The EEA can be characterized as a mark of change in policy toward more labor immigration, reinforced through EU membership.

Although total intra-EU migration comprised a small share (less than $2 \%$ ) of total migration in the 1990s and 2000s (Cerna 2009), the free movement agreement may still have changed the composition of immigrants in member countries. This seems plausible in the case of Sweden because the composition of immigration may have changed as immigration policies in Sweden before 1995 mainly favored refugees and family-reunification movers. In Sweden, immigrants from the EU-15 accounted for $9-13 \%$ of all new immigrants between 2000 and 2015 (Statistics Sweden 2016, see Figure 4 in Appendix 1).

This trend toward a more integrated European labor market has continued with the enlargement of the EU to include Eastern European countries beginning in 2004 (EU27) and special expert tax systems in Sweden aimed at attracting highly skilled labors (Mahroum 2001; Forskarskattenämnden 2013). The EU expanded dramatically in 2004, with 10 new member countries, and Sweden is one of the few EU-15 countries (the other two are the UK and Ireland) that allows free immigration for the new member countries (Ruhs 2016). This, however, had only a modest effect on immigration, as, according to Gerdes and Wadensjö (2008), about 10,000 migrant workers came to Sweden from the new EU member states.

\section{Literature review}

Many studies examine how changes in migration policies have induced migration shifts but the results are ambiguous. For example, Mayda (2010) finds that migration quotas matter because they mitigate supply-side effects. Giordani and Ruta (2010) argue that restrictive immigration policies tend to worsen the skill composition of immigrants. Djajic (1989) indicates that, by relaxing qualitative restrictions (i.e., admission is based largely on skills) on immigration, the labor-importing country may in fact improve the quality of its labor force and reduce the flow of migrants across the border. Kato and Sparber (2013) find that restrictive immigration policy (tightening of $\mathrm{H}-1 \mathrm{~B}$ visa grants for prospective undergraduate students) disproportionately discourages high-ability 
international students from pursuing education in the USA. By contrast, Chen (2005), based on a survey of Chinese graduate students, finds that master's degree students who intended to migrate to the USA are likely to be negatively self-selected in a less restrictive migration regime and positively self-selected in a more restrictive regime. Borjas (1993) argues that the Canadian point system does not help in attracting more highly skilled workers from a particular source country compared with the USA, which does not use this kind of migration policy. However, it alters the national-origin mix of the immigrant flow, which reduces the proportion of immigrants from regions that generate flows of those who are low skilled. This explains why, on average, immigrants in Canada are more highly skilled than those in the USA.

European migration policies have changed drastically over the last two decades, creating large intra-European migration flows, especially from new EU member countries in Eastern Europe to old members with higher income levels in the past decade. These policy changes create natural experiments which provide opportunities to study the impact of migration policies. For example, Elsner (2013a) examines the impact of EU enlargement in 2004 on wage distribution for non-migrants in the sending country. Using Lithuanian household data and immigration data from the UK and Ireland, he finds that emigration significantly raised wages on average for stayers; however, the wage effect was only significant for male workers. In an accompanying paper (Elsner 2013b), he also finds that the effect was concentrated among young workers, whose wages increased by $6 \%$ over the period of 5 years, while the older workers were not affected. Moreover, he finds emigration has no significant effect on the wage distribution between high- and low-skilled workers. Nevertheless, Dustmann et al. (2015) find emigration has a positive effect on wages for high- and medium-skilled workers stayed in Poland but might have a negative effect on workers at the low end of skill distribution.

However, empirical evidence on how liberalization of migration among more economically integrated and developed European countries affects the skill composition of immigrants is sparse. Based on survey data on immigrants who arrived between 1988 and 2002, Huber and Bock-Schappelwein (2014) find that after Austria became a member of the EEA in 1994, the share of permanent migrants from the EEA to Austria with low education levels dropped compared to the change in the share of low-educated permanent migrants from other countries. They therefore argued that liberalizing migration may be an effective way to improve the skill structure of immigrants in countries that have a high share of low-skilled immigrants. By contrast, Beerli and Indergand (2014) find that the abolition of quotas for workers from European countries through a bilateral agreement with the EU in 2002 had a small but negative effect on the educational quality of immigrants to Switzerland. They attribute this decline to more selective immigration policies before 2002, which in turn stem from higher returns to education in Switzerland. The differing experiences of the two countries indicate that pre-reform migration patterns are quite important for understanding how liberalization changes migration flows.

Few studies address the impact of migration policy with respect to inventive behavior. One study we know is by Jahn and Steinhardt (2016). They examine the impact of immigration on innovation by exploiting a placement policy for ethnic German immigrants, who are mainly from the former Soviet Union. They find immigrants had no or even positive effect on innovation (number of patents), although the majority of 
immigrants are unskilled. This may be because quite high share of these immigrants had worked as engineers and they have less cultural and language problems compared with other immigrants.

\section{Theories on immigration}

The workhorse model for understanding selection patterns in immigration flows is Borjas' (1987) model of self-selection of migrants. This model assumes that the costs of migration are positively related to the skill level. The model assumes that immigrants who move for work reasons will tend to move to a destination country that offers wages above those of their home country corresponding to their skill levels. Positive selection is defined as such when immigrants to the destination country are drawn from the upper tail of the income distribution in their home country and end up in the upper tail in the destination country. Conversely, negative selection is defined as the case where immigrants are from the lower tail of income distribution in the home country and end up in the lower tail in the destination country. Borjas (1987) shows that positive selection takes place if the correlation between the positions in the skill distribution to that of the income distribution in the home country and destination country are high and the income distribution at the destination country is higher. The opposite takes place if the correlation again is high but the distribution of income is lower in the destination country. ${ }^{6}$

Swedish income distribution is more compressed and low-skilled people are (generally) rewarded more generously than that of the majority of other countries in the world, including the EU-15 countries. Therefore, negative selection of immigrants to Sweden seems to be the main theoretical implication according to Borjas' (1987) model. However, his model is based on an assumption of free mobility and increasing costs by skill level. This assumption is debatable, and we would like to have a further discuss about it.

The nature of the moving cost to Sweden and its relation to skills before and after the EEA are important because they influence the payoff involved in moving. The distribution of the moving cost for different skill levels before the EEA and the change in the distribution of the cost reductions implied by the EEA may differ by skill levels and is important for the outcome.

International migration cost includes actual moving costs (e.g., cost of visa application), information searching cost (e.g., time spent on searching the process of visa application), social networks cost (e.g., give up part of social network in the home country), and adoption costs (e.g., learning a new language and institutions) in the host country $^{7}$ (McKenzie and Rapoport 2010). For citizens from the EU-15, it is hard to see that actual moving costs and social network costs are systematically related to the skill level. However, information searching costs and adoption costs are likely to be negatively related to an individual's skills. For example, highly educated individuals are usually easier to find the necessary information for migration and better at learning a new language and institutions. Nevertheless, highly educated individuals also often demand more knowledge about institutions and may invest more in education to adopt to the new country. Total adaptation costs may not be fully known before someone moves and could vary from one individual to another, but it surely plays a role in the decision to move. Overall, it seems plausible that migration costs to Sweden are not systematically related to skills. 
Importantly, the implication that costs rise with the skill level also seems to be at odds with generally observed migration patterns. They tend to show that selection is overall positive, even in cases where one would expect to observe more negative selection patterns, according to empirical data on world migration flows reported by Grogger and Hanson (2011). Grogger and Hanson (2011) develop an alternative model in which moving costs are considered fixed and unrelated to the skill level. In Appendix 2, we modify this model to account for our assumption that the fixed cost of moving is likely to be lowered more for low-skilled workers. The implication of this, combined with the assumption that the net wage difference for highly skilled workers relative to low-skilled workers does not increase in Sweden as compared to EU-15 countries, is that a higher share of EU-15 citizens with low skills could be attracted to Sweden after the liberalization of migration after the inception of the EEA in 1994.

\section{Data and descriptive analysis}

\subsection{Variable construction}

This paper takes advantage of a unique database that links inventors to the general population in Sweden from 1985 to 2007 (Jung and Ejermo 2014; Zheng and Ejermo 2015). The data on inventors and inventions were extracted from the Worldwide Patent Statistics (PATSTAT) database provided by the European Patent Office (EPO). If an immigrant is listed as an inventor on at least one patent application to the EPO at any time since the time of his/her migration until 2007, s/he is considered an inventor. Here, we use patent application data instead of data on patents granted as it usually takes long time for a patent to be granted (on average, 5 years in our data).

The linkage between inventors and the population is done by two steps. First, inventors' social security numbers $(\mathrm{SSNs})^{8}$ were identified by matching the names and addresses provided by the EPO to those offered by a commercial company or a 1990 Swedish population directory. Second, inventors were linked to the entire population in terms of their SSNs. Detailed personal information on inventors and population was obtained from Statistics Sweden, which has collected such information for all Swedish residents from 1985 onwards. Finally, among the identified inventors, 10.9\% are foreign-born who contributed to $11.6 \%$ (by fractional count) of the identified Swedish patent applications (Zheng and Ejermo 2015). ${ }^{9}$

We focus on those who immigrated at the age of 18-64 in the period 1990-2007 (1985-2007 in the descriptive analysis) as these immigrants could be potentially in the workforce. Compared with immigrants from other regions, immigrants from the EU-15 who migrated at the above ages are more likely to be economic migrants. This can be shown by their higher employment rates (around 62-66\% within 2 years of migration between 1985 and 2007, including both fully and partly employed) in Table 7 in Appendix 1.

We use education data to proxy for skills at the time of immigration. As data on immigrants' education level at the time of migration are not well registered, we imputed the missing data as follows. First, if immigrants have not enrolled in any education in Sweden after they arrived, we assumed their education levels at the time of migration are the same as the first record shown in later years. Second, if immigrants enrolled in secondary high school education in Sweden after they arrived, we assumed they had primary education before they arrived. Third, if immigrants enrolled in post-secondary 
high school ( $\geq 13$ years of schooling) after they arrived, we expected that they had a secondary high school education (10-12 years of schooling) before they arrived. In total, we imputed $42 \%$ of data on education level for immigrants at the time of migration. Figure 5 shows that the percentage of missing data on education level in each year becomes more homogenous based on imputed data compared with the shares of missing observations in the original data. In addition, by comparing the regression results with and without imputation (Tables 2 and 4 vs. Table 8), it seems unlikely that we create problems by using the imputed data, although potential imputation mistakes on data may still exist (see the detailed discussion in the last paragraph of Section 7.1).

We measure the skill composition of immigrants in two ways. First, we compare the education structure of immigrants before and after the liberalization on three education levels. They are as follows: (a) the low educated: immigrants who arrived with education that ends up at primary school ( $\leq 9$ years of schooling); (b) the middle educated: those who arrived with a secondary school education; and (c) the high educated: those who arrived with a post-secondary school education. In addition, we also use inventor data to investigate the effect of the liberalization reform on skills, which has not been done before. In this way, we investigate the probability that an immigrant will become an inventor between the time of their immigration and the end of the study period (i.e., 2007).

When it comes to data on origin of immigrants, we can only observe data on broad region of origin rather than on the country level. Knowing the country of origin would also have been useful in order to control for or examine country-specific effects. The division of region of origin and inflow of immigrants for each group are as follows:

(a) “The EU-15”. Finland, Denmark, and Sweden (the destination country) are excluded because they are part of the Nordic country, where free movement policy enacted in 1954. The EU-15 is our treatment group affected by the migration reform in 1994.

(b) "Other developed regions". This includes the other Nordic countries (Finland, Denmark, Norway, and Iceland), North America (Canada, the USA, Central America, and the Caribbean countries), and Oceania.

(c) "All other regions" (excluding the rest of Europe and the former Soviet Union (SU)). This group includes "Other developed regions" (group b) as well as Asia, Africa, and South America.

(d)The rest of Europe and the former SU.

\subsection{Trends in immigration group composition}

Figure 1 shows number of immigrants over time by region of origin as defined above. We can observe that:

First, migration from the EU-15 to Sweden shows a stable increase over the whole period. This increase took place after 1995. In fact, immigration from the EU-15 more than doubled by 2006 .

Second, the migration trend for "Other developed regions" is also quite stable and largely in line with that of the EU-15. The main difference is that during the period 1988-1990, a relatively large inflow of immigrants from Denmark and Norway occurred (Statistics Sweden 1989, 1990, 1991). We use this group as our benchmark comparison to that of the EU-15. 


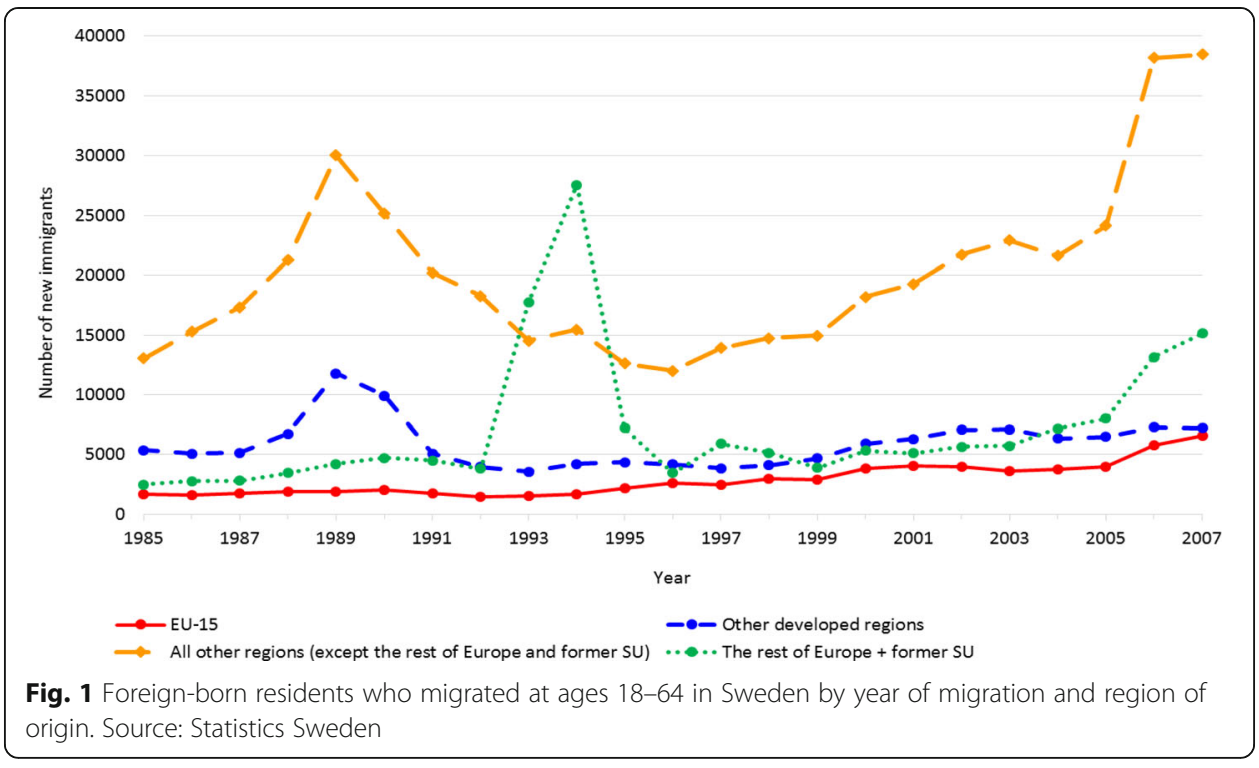

Third, migration from "All other regions" (which also includes "Other developed regions") shows a high level of fluctuation. It has an even sharper spike in 1989. This is because of a large inflow of refugees from developing countries, such as Chile and Lebanon (Statistics Sweden 1989, 1990, 1991). The boom in 2006 is mainly due to large increases in refugees from countries such as Iran, Iraq, Lebanon, and Somalia (Statistics Sweden 2016). Therefore, the group of "All other regions" is not a good choice for comparison because of its large heterogeneity. Immigration from this group occurs more often for humanitarian reasons, and data could be more erratic. However, we still included the group as a robustness check to compare with the results which use "Other developed regions" as a baseline. As expected, the empirical results (available upon request) are quite noisy. ${ }^{10}$ Therefore, we do not report on the empirical results on this part.

Finally, for the rest of Europe and the former SU, we see that, as in Austria (Huber and Bock-Schappelwein 2014), a massive inflow of immigrants took place in 1993 and 1994 because of the large number of refugees that resulted from the breakup of Yugoslavia and the ensuing wars. Immigrants from the former SU also doubled in 1991 compared with 1990 because of the breakup of the SU (Statistics Sweden 2016). This influx of immigrants may have differed substantially from other immigrant flows in terms of motivation and education. ${ }^{11}$ It is clear that refugee waves can distort the interpretation of policy reforms that we study. Therefore, we exclude this group in the regression analyses when compared with immigrants from the EU-15. ${ }^{12}$

Figure 2 shows the proportion of low-, middle-, and high-education levels the year of immigration for each immigrant group by region of origin. For comparison, it also shows the proportion of each education level for the Swedish-born population. Subgraph A shows that the share of the low-educated drops markedly for all groups over time. It is clear that the developed regions have lower shares of the low educated. The EU-15 experienced a marked fall in the share of the low educated in the 1989-1993 period, followed by a small hike in the 1994-1995 period, seemingly corroborating our theoretical prediction. There is a similar trend for immigrants from the rest of Europe and the former $\mathrm{SU}$ in those years. It is possible that those changes are due to the 


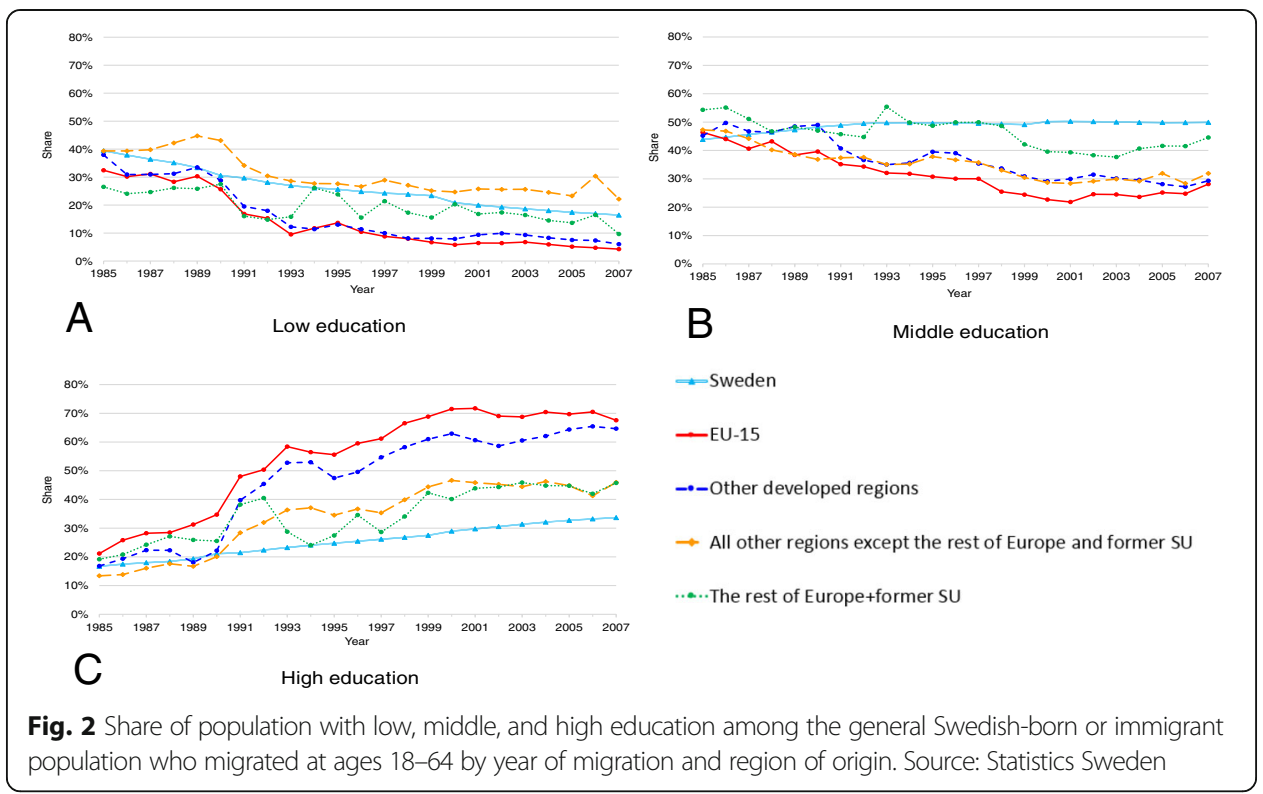

refugee crisis in the former Yugoslavia, democratization of formerly communist regimes in Eastern Europe, and the loosening of emigration restrictions on those regions.

Like graph A, graph B shows declining trends with respect to the share of middleeducated immigrants for each immigrant group. By contrast, the trend in middleeducated Swedish born is rising. This is explained by the fact that nowadays, almost every young person has had a secondary (gymnasium) education, which is now seen as almost a prerequisite for getting a job. Simultaneous with a large increase in immigrants in 1993 and 1994, the share of middle-educated immigrants in 1993 from the rest of Europe and the former SU experienced a spike. This group maintained a stable, relatively high level through 1998, before falling in 1999-2003, and then showed an increase. Among immigrants from "Other developed regions" and "All other regions," the years 1992-1995 displayed a U-shaped pattern. However, for the EU-15, the share consistently decreased until 2001, after which a slight increase can be observed.

Unlike graphs $\mathrm{A}$ and $\mathrm{B}$, graph $\mathrm{C}$ shows generally growing trends in the shares of the highly educated in each group over the whole period. The share of the highly educated in each immigrant group was higher than for the Swedish population after 1990, seemingly reinforcing Grogger and Hanson's (2011) conclusion that emigrants generally draw from the highly educated part of the distribution. Again, the rest of Europe and the former SU showed a somewhat irregular pattern, increasing sharply in 1991-1992 and then dropping sharply in 1993 and 1994. The highest share of the highly educated immigrant group comes from the EU-15. Interestingly, this group showed a declining share of highly educated in the period 1993-1995, but a decline is also observed for "Other developed regions" and "All other regions" in the period 1994-1995. These patterns suggest that other things were going on at the period of observation and reinforce the need to control for underlying trends.

Of the identified foreign-born inventors, 23.3 and 31.5\% came from the EU-15 and "Other developed regions," who contributed 24.1 and $30.8 \%$ of the identified Swedish patent applications (by fractional count), respectively. Figure 6 in Appendix 1 shows a growing trend of patent applications by the above two groups as well as by the 
Swedish-born inventors since 1994. This may be related to the economic recovery from financial crisis at the beginning of 1990 as well as Sweden's accession into EEA, which have led to an increased inflow of highly skilled immigrants from the EU-15 members to Sweden.

In sum, the descriptive analysis shows that, after the EEA was formed in 1994, the number of immigrants from the EU-15 increased slightly, with an increase in the share of low-educated immigrants and decrease in the share of the middle and highly educated during 1994 to 1995 , although the absolute number of immigrants in each education level grew.

\section{Methods and data for regression analysis}

Additional evidence on the impact of this policy change on the skill structure of immigrants in Sweden from the EU-15 can be obtained using a DiD regression approach. Here, we exploit the fact that, in 1994, only immigration from the EU-15, but not from outside the EU-15, was affected by Sweden's accession to the EEA. We divide the data into a subset of region that was affected by the reform (the EU-15) and another subset that was not affected ("Other developed regions"). Our study period is 1990-1997, or alternatively 1990-2007, and we group the time period into a pre (1990-1993)- and a post (1994-1997 or 1994-2007)-membership period. We start in 1990 due to the availability of data on control variables (marriage and children). ${ }^{13}$ Moreover, inventor data in this dataset is complete until 2007. Extending the investigation period beyond 1997 allows us to distinguish whether any effects are short or long term.

We estimate the impact of the EEA accession on the EU-15 immigrants' skills in Sweden by studying the probability that an immigrant would be low, middle, or highly educated as well as the probability of his/her becoming an inventor after migration and until 2007. The DiD estimation can be described as

$$
y_{i j t}=\alpha D_{\mathrm{EU}-15} \cdot D_{t \geq 1994}+\beta_{t} Y_{t}+y_{j} D_{j}+\lambda X_{i}+\rho H_{j t}+\varepsilon_{i j},
$$

where $y_{i j t}$ is a dummy variable indicating whether an immigrant $(i)$ from region $(j)$ at the time of migration $(t)$ is low, middle, or highly educated or becomes an inventor after migration. $Y_{t}$ is a set of migration year-fixed effects. These pick up influences stemming from, for example, business-cycle variations that may influence the skills of immigrants. $D_{j}$ is a vector of dummy variables for each region of origin that captures unmeasured region-fixed effects. $X_{i}$ is a set of individual characteristics at the time of migration that may affect the probability of observing a certain level of education or of being an inventor. $X_{i}$ includes the variables female $\left(1=\right.$ female, $0=$ male), age, age ${ }^{2}$, marital status ( 1 = married, $0=$ unmarried), and children $(1=$ at least having one child, $0=$ no children) at the time of migration. These are included to control for skill differences that stem from gender, life-cycle effects, and socioeconomic background. $H_{j t}$ is an index of weighted human capital based on the average number of years of schooling and estimated rates of return to education from the Penn World Tables (Feenstra et al. 2015). Since we observe region of immigrants and not their country of origin, we construct a weighted human capital measure for each region, based on population size. ${ }^{14}$ This index controls for supply-side and trends in skills effects that influence the skill level of immigrants. $D_{t \geq 1994}$ is a dummy variable with a value of 1 if an immigrant migrated in 1994 or later. $D_{\mathrm{EU}-15}$ is a dummy variable with a value of 1 if an immigrant 
is from the EU-15. $\beta_{t}, \gamma_{j}, \lambda$, and $\rho$ are parameters to be estimated; $\varepsilon_{i j}$ is an error term. $\alpha$ is the central parameter of interest. This measures the average change in $y_{i j t}$ on the treated relative to the untreated migrant groups. If $\alpha$ is statistically significantly different from 0, the examined skill for immigrants coming from the EU-15 in 1994 or later are found to be different from the EU-15 immigrants coming before 1994 and from immigrants from other regions.

Table 1 shows a descriptive analysis of dependent and control variables by period and region of origin. We compare the EU-15 with "Other developed regions" 4 years before and after the accession to the EEA in 1994 (1990-1993 vs. 1994-1997). For example, compared with before treatment, the mean value of low education for the EU-15 decreased by 0.07 percentage points after 1994, while for "Other developed regions," it decreased by 0.12 percentage points. For the EU-15, the share of inventors among immigrants increased from $0.6 \%$ before the EEA to $1 \%$ after the EEA, while the increase in percentage terms was much smaller for immigrants from "Other developed regions" (from 0.2 to $0.3 \%$ ).

The immigrant age is very stable at around 29-30 years on average, both before and after 1994. Immigrants are roughly balanced by gender from "Other developed regions" both before and after 1994. By contrast, male immigrants dominate strongly from the EU-15 both before and after 1994 (around 60\%). Finally, it is as common for immigrants from the EU-15 as for immigrants from "Other developed regions" to have a child at the time of migration, with a slowly declining share after the EEA for both groups.

Our regressions use two basic models for each dependent variable. The first model excludes while the second model includes all control variables $X_{i}$ and weighted human capital. The comparison of these two models is done to gain and understanding of how the control variables $X_{i}$ and weighted human capital affect the skill composition of immigrants. For simplicity, we use the linear probability model (rather than probit or logit models), as we are only interested in the average treatment effect of the EEA, and these are directly given by our estimated coefficient.

Table 1 Descriptive statistics for dependent and control variables by periods and region of origin

\begin{tabular}{|c|c|c|c|c|c|c|c|c|}
\hline & \multicolumn{4}{|c|}{ Before treatment (1990-1993) } & \multicolumn{4}{|c|}{ After treatment (1994-1997) } \\
\hline & \multicolumn{2}{|l|}{ EU-15 } & \multicolumn{2}{|c|}{ Other developed regions } & \multicolumn{2}{|l|}{$\overline{E U}-15$} & \multicolumn{2}{|c|}{ Other developed regions } \\
\hline & $\overline{\text { Mean }}$ & S.D. & $\overline{\text { Mean }}$ & S.D. & $\overline{\text { Mean }}$ & S.D. & $\overline{M e a n}$ & S.D. \\
\hline Low education & 0.18 & 0.38 & 0.23 & 0.42 & 0.11 & 0.32 & 0.11 & 0.32 \\
\hline Middle education & 0.36 & 0.48 & 0.44 & 0.50 & 0.31 & 0.46 & 0.37 & 0.48 \\
\hline High education & 0.46 & 0.50 & 0.33 & 0.47 & 0.58 & 0.49 & 0.51 & 0.50 \\
\hline Inventor & 0.006 & 0.076 & 0.002 & 0.045 & 0.010 & 0.101 & 0.003 & 0.053 \\
\hline Age & 29.16 & 7.78 & 29.02 & 8.58 & 30.36 & 7.87 & 29.92 & 8.59 \\
\hline Female & 0.40 & 0.49 & 0.49 & 0.50 & 0.39 & 0.49 & 0.51 & 0.50 \\
\hline Married & 0.38 & 0.49 & 0.29 & 0.45 & 0.35 & 0.48 & 0.33 & 0.47 \\
\hline Children & 0.24 & 0.43 & 0.25 & 0.43 & 0.23 & 0.42 & 0.23 & 0.42 \\
\hline Observations & 4,845 & & 14,614 & & 6,156 & & 9,651 & \\
\hline
\end{tabular}

Source: Statistics Sweden and CIRCLE data on inventors $S D$ standard deviation 


\section{Empirical results}

\subsection{Results for education}

Table 2 shows the main results, where we use the period 1990-1997 in the regressions. The probability that an immigrant from the EU-15 was low educated clearly increased compared to immigrants from "Other developed regions" after Sweden's accession to the EEA (models 1.1 and 1.2).

The probability of observing that an immigrant from the EU-15 was middle educated decreased significantly $(p<0.05)$ relative to those from "Other developed regions" without including control variables (model 2.1). However, when controlling for other variables, the effect turns insignificant (model 2.2).

Finally, with respect to the probability of being highly educated, it shows that the probability that immigrants from the EU-15 were highly educated decreased significantly $(p<0.05)$ compared to those from "Other developed regions" when control variables are held constant (model 3.2). In sum, the effect for the 1990-1997 period on the education composition of immigrants from the EU-15 after accession to the EEA follows our expectations when we use "Other developed countries" as our baseline. The effects are also economically significant. We see an average increase of $3.6 \%$ of immigrants with low education (model 1.2) and a decrease of $3.7 \%$ of immigrants with high education (model 3.2) from the EU-15 compared to those from "Other developed regions" after Sweden's accession to the EEA in 1994.

Table 2 Linear probability models for migrants aged 18-64 being low, middle, or highly educated at the time of migration, 1990-1997

\begin{tabular}{|c|c|c|c|c|c|c|}
\hline & \multicolumn{6}{|c|}{ Control: Other developed regions } \\
\hline & $\overline{1.1}$ & 1.2 & 2.1 & 2.2 & 3.1 & 3.2 \\
\hline & Low1 & Low2 & Mid1 & Mid2 & High1 & High2 \\
\hline \multirow[t]{2}{*}{ EU-15 × 1994-1997 } & $0.021^{* *}$ & $0.036^{* * *}$ & $-0.023^{* *}$ & 0.001 & 0.001 & $-0.037^{* *}$ \\
\hline & $(0.008)$ & $(0.011)$ & $(0.011)$ & $(0.016)$ & $(0.011)$ & $(0.016)$ \\
\hline \multirow[t]{2}{*}{ Age at migration } & & $-0.040^{* * *}$ & & $-0.043^{* * *}$ & & $0.083^{* * *}$ \\
\hline & & $(0.002)$ & & $(0.002)$ & & $(0.002)$ \\
\hline \multirow[t]{2}{*}{$\mathrm{Age}^{2}$ at migration } & & $0.001^{* * *}$ & & $0.000^{* * *}$ & & $-0.001^{* * *}$ \\
\hline & & $(0.000)$ & & $(0.000)$ & & $(0.000)$ \\
\hline \multirow[t]{2}{*}{ Female } & & $-0.037^{* * *}$ & & $0.030^{* * *}$ & & 0.007 \\
\hline & & $(0.004)$ & & $(0.005)$ & & $(0.005)$ \\
\hline \multirow[t]{2}{*}{ Marriage } & & $-0.024^{* * *}$ & & 0.004 & & $0.020^{* * *}$ \\
\hline & & $(0.005)$ & & $(0.006)$ & & $(0.006)$ \\
\hline \multirow[t]{2}{*}{ Children } & & $0.110^{* * *}$ & & $-0.037^{* * *}$ & & $-0.073^{* * *}$ \\
\hline & & $(0.006)$ & & $(0.007)$ & & $(0.006)$ \\
\hline \multirow[t]{2}{*}{ Human capital } & & $-1.184^{*}$ & & -1.113 & & $2.297^{* *}$ \\
\hline & & $(0.619)$ & & $(0.914)$ & & $(0.919)$ \\
\hline Year of immigration FE & Yes & Yes & Yes & Yes & Yes & Yes \\
\hline Region of origin FE & Yes & Yes & Yes & Yes & Yes & Yes \\
\hline Observations & 35,266 & 35,266 & 35,266 & 35,266 & 35,266 & 35,266 \\
\hline Adjusted $R^{2}$ & 0.206 & 0.233 & 0.407 & 0.434 & 0.501 & 0.535 \\
\hline
\end{tabular}

Robust standard errors in parentheses. Note (for all regression tables): Coefficient results are reported. Source: Statistics Sweden

${ }^{* * *} p<0.01$; ${ }^{* *} p<0.05 ;{ }^{*} p<0.1$ 
One of the critical aspects of the $\mathrm{DiD}$ approach is the validity of the so-called common trend or parallel trend assumption (Angrist and Pischke 2009). Without parallel trends in the outcome variable before a reform, it is no longer clear that something that affected the outcome after the reform is not influenced by trends that existed before the liberalization reform. Table 3 tests the common trend assumption with another set of regressions. Those regressions are based on the idea that the addition of year dummies multiplied by the treatment dummy (i.e., EEA) should not be significant if year effects and group dummies pick up trend effects (Granger 1969; Angrist and Pischke 2009). This modifies our estimated equation to

$$
y_{i j t}=\beta_{t} Y_{i t}+\gamma_{j} D_{j}+\lambda X_{i}+\rho H_{j t}+\sum_{\tau=0}^{m} \delta_{-\tau} D_{i, t-\tau}+\sum_{\tau=2}^{q} \delta_{+\tau} D_{i, t+\tau}+\varepsilon_{i j}
$$

where the first summation term captures lagged effects and the second captures lead effects. Note that lagged effects now replace the original treatment effect $\left(D_{\mathrm{EU}-15} \cdot D_{t \geq}\right.$ 1994) and that we omit the first lead effect (i.e., 1993), which is then the baseline year against which we compare the effects.

If lead terms (i.e., prior to 1994) are statistically significant, the common trend assumption is in doubt. In Fig. 3, we depict the lead and lag effects estimated for models 1.2, 2.2, and 3.2 in Table 3.

In sum, most of the lead effects are statistically insignificant. The point estimate most close to 0 is the low educated. For the middle educated, there seems to be slight tendency of an increase before 1993, whereas 1990 is statistically significantly different from $0(p<0.05)$, with a point estimate of $-4.9 \%$. For the highly educated, there is a slight negative trend in the point estimates prior to 1993, with a statistically significant $(p<0.05)$ effect of $+4.7 \%$ in 1990. The most robust result is therefore for the low educated. The lagged effects are very interesting as well. For the low educated, we see that the strongest positive probability effect is found for 1994 and 1995 (periods 0 and 1, respectively), that is, closest to the reform change. These are estimated at $+4.3 \%$ and are statistically significant at the $1 \%$ level, while the effects in 1996 and 1997 are smaller (around $+3 \%$ ) and only statistically significant at the $10 \%$ level. For the middle educated, we see no significant effects among the lagged effects and the point estimates do not seem to display a systemic pattern when holding other variables constant. For the highly educated, we see a $5.2 \%$ decline in 1994, which is statistically significant at the 5\% level, whereas the lagged effects for 1995 and 1996 are not statistically significant and are close to 0, although the effect for 1997 turns more negative but is not statistically significant at the $10 \%$ level. In sum, these results suggest that the common trend assumption is not seriously challenged and that the effects on the low- and highly educated immigrants are the strongest during the first years after the liberalization of migration. The fact that the effect is strong in the early years of the reform supports the conclusion that the liberalization indeed had an effect on the skill composition of new EU-15 immigrants to Sweden.

Table 4 extends the post-1994 period to 2007. The extension affects the interaction dummy and has the implication of understanding that whether the EEA had long-run effects. If the estimated coefficient $\alpha$ is close to 0 , it suggests that the effects that we 
Table 3 Linear probability models with lead and lag effects for migrants aged 18-64 being low, middle, or highly educated at the time of migration, 1990-1997

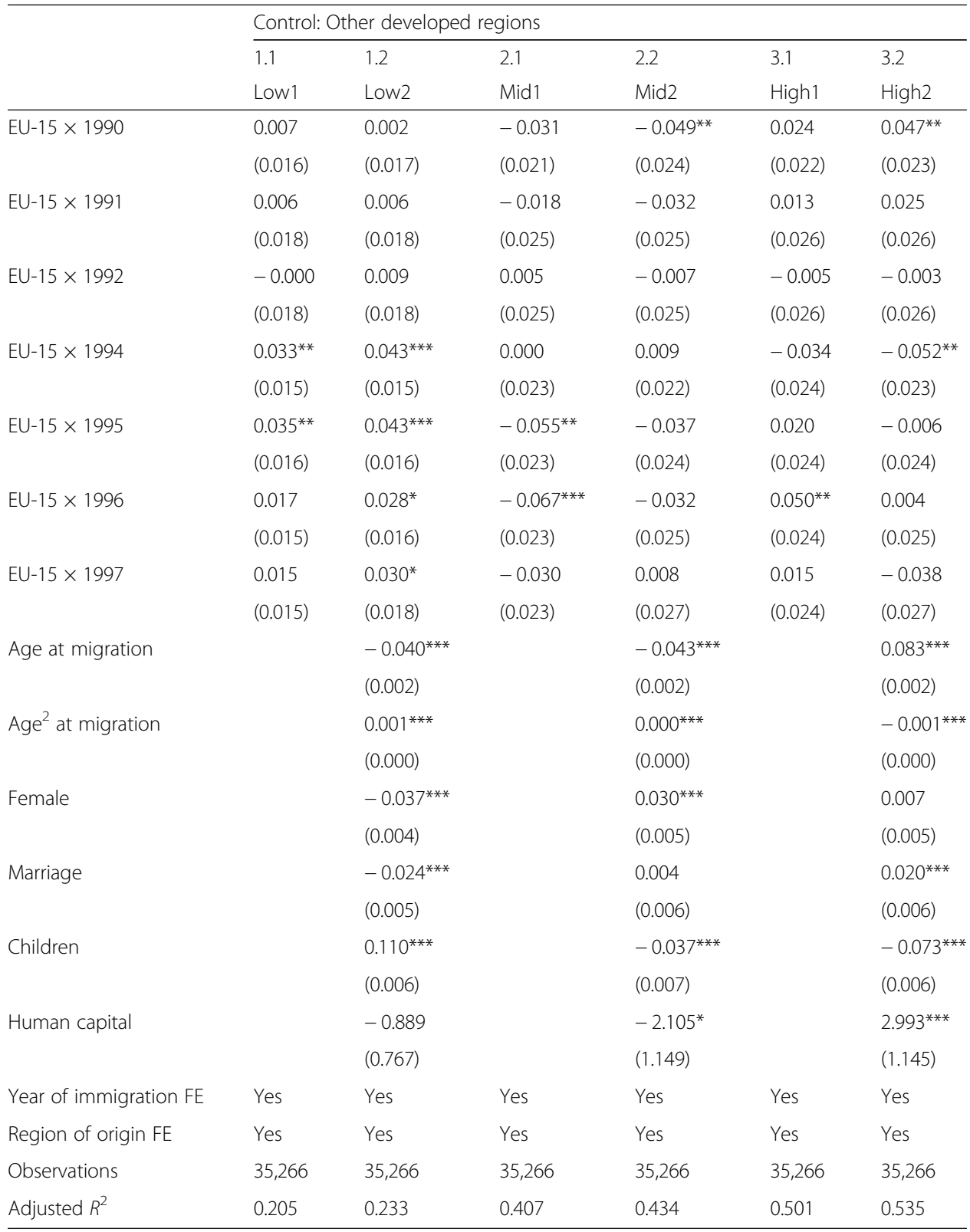

Robust standard errors in parentheses. Note: EU-15 $\times 1993$ is the reference group. Source: Statistics Sweden ${ }^{* * *} p<0.01 ;{ }^{* *} p<0.05 ;{ }^{*} p<0.1$

find in Table 2 are, instead, more transitory. The results in Table 4 indicate that it seems safe to claim that the effects are indeed somewhat transitory; although there is still significantly positive impact $(p<0.1)$ on the probability that immigrants from the EU-15 were low-educated and significantly negative impact $(p<0.01)$ on the probability that immigrants from the EU-15 were highly educated relative to those from "Other developed regions" when other variables are held constant, however, the coefficients are much lower for each of them $(+1.2 \%$, model $1.2 ;-2.5 \%$, model 3.2$)$ and the small significant differences are mainly attributed to the first years of liberalization (see Table 3). For the middle educated, the main difference concerns the fact that, without controls, the effect now is 


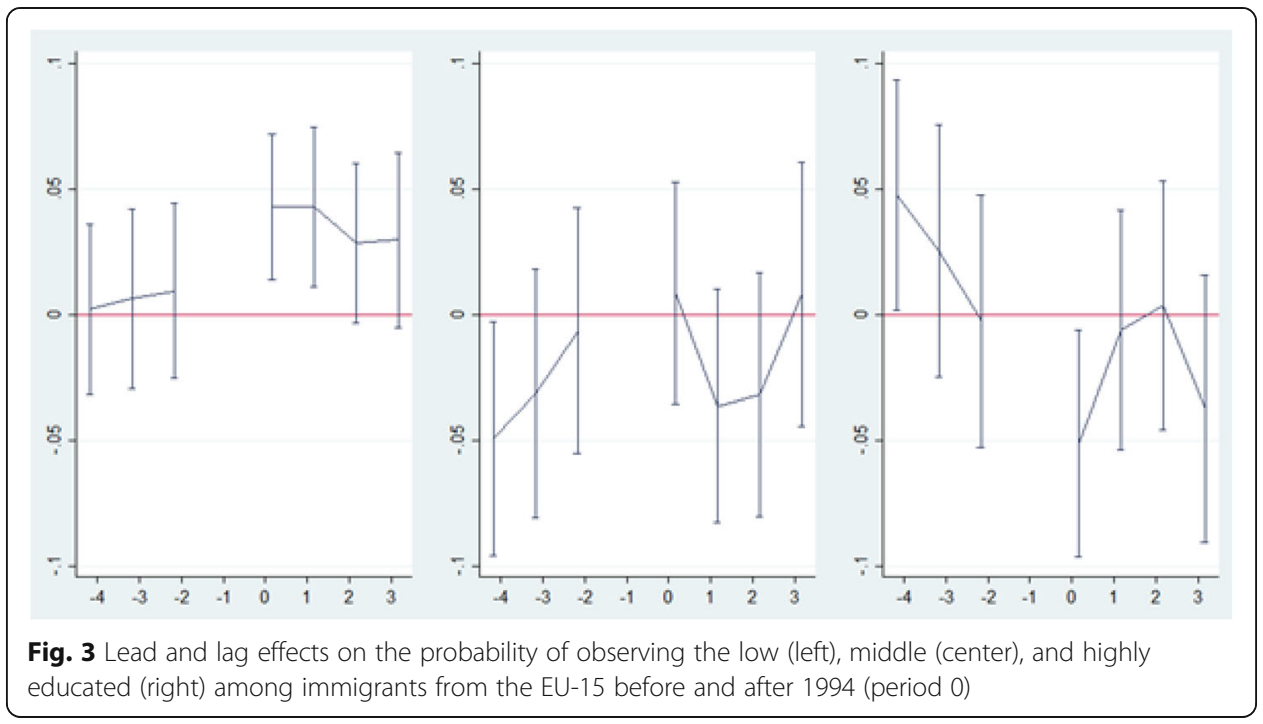

not significantly different from 0 any more (model 2.1). In sum, it seems there is no longrun impact on the educational profile of new immigrants from the EU-15.

We have also done a robust check only based on data for immigrants whose education level is available at the time of migration (i.e., no imputation on education data) for both periods of 1990-1997 and 1990-2007 (see Table 8). The results for the probability that immigrants from the EU-15 being highly educated compared to those from "Other developed regions" is similar when using imputed data (models 1.3 and 2.3 in Table 8 vs. model 3.2 in Tables 2 and 4). That is, the probability of immigrants from the EU-15 being highly educated decreased significantly $(p<0.01)$ when control variables are held constant. However, there is some difference with respect to the probability of being low and middle educated. The significant difference on the probability of an immigrant being low educated between immigrants from the EU-15 and "Other developed regions" disappeared when using original data (models 1.1 and 2.1 in Table 8 vs. model 1.2 in Tables 2 and 4). We also find that the probability that immigrants from the EU-15 were more likely to be middle educated than those from "Other developed regions" $(p<0.01)$ increased when using original data (models 1.2 and 2.2 in Table 8 vs. model 2.2 in Tables 2 and 4). Despite these differences for low and middle educated, we argue that the imputed data are more accurate as shown by more consistent time series (see Figure 5).

\subsection{Results for inventors}

Table 5 examines the probability that an immigrant will become an inventor from the time of migration until 2007, based on patent application data. On the left-hand side of the table, we use the period 1990-1997 and on the right-hand side 1990-2007.

We find that immigrants from the EU-15 have a $0.4 \%$ higher probability of becoming inventors compared with immigrants from "Other developed regions" when variables $X_{i}$ and weighted human capital are not controlled for in the short run (1990-1997) (model 1.1). However, we see a negative but not significant effect in our main model 1.2, where other variables are held constant. It turns negative and insignificant after the inclusion of human capital (the coefficient of $\alpha$ is still positively significant when we include only 
Table 4 Linear probability models for migrants aged 18-64 being low, middle, or highly educated at the time of migration, 1990-2007

\begin{tabular}{|c|c|c|c|c|c|c|}
\hline & \multicolumn{6}{|c|}{ Control: Other developed regions } \\
\hline & 1.1 & 1.2 & 2.1 & 2.2 & 3.1 & 3.2 \\
\hline & Low1 & Low2 & Mid1 & Mid2 & High1 & High2 \\
\hline \multirow[t]{2}{*}{ EU-15 × 1994-2007 } & 0.008 & $0.012^{*}$ & -0.002 & 0.012 & -0.006 & $-0.025^{* * *}$ \\
\hline & $(0.007)$ & $(0.007)$ & $(0.009)$ & $(0.009)$ & $(0.009)$ & $(0.009)$ \\
\hline \multirow[t]{2}{*}{ Age at migration } & & $-0.028^{* * *}$ & & $-0.054^{* * *}$ & & $0.082^{* * *}$ \\
\hline & & $(0.001)$ & & $(0.001)$ & & $(0.001)$ \\
\hline \multirow[t]{2}{*}{$\mathrm{Age}^{2}$ at migration } & & $0.000^{* * *}$ & & $0.001^{* * *}$ & & $-0.001^{* * *}$ \\
\hline & & $(0.000)$ & & $(0.000)$ & & $(0.000)$ \\
\hline \multirow[t]{2}{*}{ Female } & & $-0.028^{* * *}$ & & $0.008^{* * *}$ & & $0.020^{* * *}$ \\
\hline & & $(0.002)$ & & $(0.003)$ & & $(0.003)$ \\
\hline \multirow[t]{2}{*}{ Marriage } & & $-0.018^{* * *}$ & & -0.001 & & $0.018^{* * *}$ \\
\hline & & $(0.003)$ & & $(0.003)$ & & $(0.004)$ \\
\hline \multirow[t]{2}{*}{ Children } & & $0.065^{* * *}$ & & -0.005 & & $-0.060^{* * *}$ \\
\hline & & $(0.003)$ & & $(0.004)$ & & $(0.004)$ \\
\hline \multirow[t]{2}{*}{ Human capital } & & $-0.319^{* * *}$ & & $-0.346^{* * *}$ & & $0.665^{* * *}$ \\
\hline & & $(0.056)$ & & $(0.096)$ & & $(0.100)$ \\
\hline Year of immigration FE & Yes & Yes & Yes & Yes & Yes & Yes \\
\hline Region of origin FE & Yes & Yes & Yes & Yes & Yes & Yes \\
\hline Observations & 103,516 & 103,516 & 103,516 & 103,516 & 103,516 & 103,516 \\
\hline Adjusted $R^{2}$ & 0.148 & 0.172 & 0.335 & 0.364 & 0.618 & 0.641 \\
\hline
\end{tabular}

Robust standard errors in parentheses. Source: Statistics Sweden ${ }^{* * *} p<0.01 ; * * 0.05 ;{ }^{*} p<0.1$

variables $X_{i}$; results are available upon requests). This suggests that the growing number of inventors from EU-15 immigrants is because of its increasing human capital, but not because of free migration. Moreover, there is no significant effect when we examine the long period (1990-2007) (models 2.1-2.2).

\subsection{Control variables}

When looking at the education level, we observe a curvilinear relationship with age at migration and education level. The higher the age at migration, the higher the probability that an immigrant is highly educated. It is the opposite result in terms of middle and low education. Female and married immigrants are more likely to be highly educated. However, immigrants with children were less likely to be highly educated. In line with expectations, an immigrant is much more likely to be highly educated if the human capital for the region of origin is higher.

When we look at the probability of becoming an inventor, age effects have coefficients very close to 0 although they are always statistically significant. In line with many other studies, we find that female immigrants are less likely to become inventors (Ding et al. 2006; Azoulay et al. 2007). Marital status and whether having a child have no significant effect on the probability of becoming an inventor. Finally, the human capital level of the country of origin has a significantly positive effect. 
Table 5 Ordinary least square (OLS) regressions of the probability of a migrant becoming an inventor from the time of migration until 2007, 1990-2007

\begin{tabular}{|c|c|c|c|c|}
\hline & \multicolumn{4}{|c|}{ Control: Other developed regions } \\
\hline & \multicolumn{2}{|c|}{ 1990-1997 } & \multicolumn{2}{|c|}{ 1990-2007 } \\
\hline & 1.1 & 1.2 & 2.1 & 2.2 \\
\hline & Pat1 & Pat2 & Pat1 & Pat2 \\
\hline \multirow[t]{2}{*}{ EU-15 × 1994-1997 } & $0.004^{* *}$ & -0.001 & & \\
\hline & $(0.002)$ & $(0.002)$ & & \\
\hline \multirow[t]{2}{*}{ EU-15 × 1994-2007 } & & & -0.000 & -0.001 \\
\hline & & & $(0.001)$ & $(0.001)$ \\
\hline \multirow[t]{2}{*}{ Age at migration } & & $0.001^{* * *}$ & & $0.001^{* * *}$ \\
\hline & & $(0.000)$ & & $(0.000)$ \\
\hline \multirow[t]{2}{*}{$\mathrm{Age}^{2}$ at migration } & & $-0.000^{* * *}$ & & $-0.000^{* * *}$ \\
\hline & & $(0.000)$ & & $(0.000)$ \\
\hline \multirow[t]{2}{*}{ Female } & & $-0.005^{* * *}$ & & $-0.004^{* * *}$ \\
\hline & & $(0.001)$ & & $(0.000)$ \\
\hline \multirow[t]{2}{*}{ Marriage } & & 0.001 & & -0.000 \\
\hline & & $(0.001)$ & & $(0.000)$ \\
\hline \multirow[t]{2}{*}{ Children } & & -0.001 & & -0.001 \\
\hline & & $(0.001)$ & & $(0.000)$ \\
\hline \multirow[t]{2}{*}{ Human capital } & & $0.363^{* * *}$ & & $0.020^{*}$ \\
\hline & & $(0.128)$ & & $(0.012)$ \\
\hline Year of immigration FE & Yes & Yes & Yes & Yes \\
\hline Region of origin FE & Yes & Yes & Yes & Yes \\
\hline Observations & 35,266 & 35,266 & 103,516 & 103,516 \\
\hline Adjusted $R^{2}$ & 0.006 & 0.009 & 0.005 & 0.006 \\
\hline
\end{tabular}

Robust standard errors in parentheses. Source: Statistics Sweden and CIRCLE data on inventors ${ }^{* * *} p<0.01 ;{ }^{* *} p<0.05 ;{ }^{*} p<0.1$

\section{Conclusions}

This paper presents evidence on the change of skill structure of immigrants to Sweden from the EU-15 as the result of the implementation of the EEA in 1994, which allows free mobility among member countries. We use both education and inventor data to infer changes in skill levels.

Using DiD regressions, we find that the education level of immigrants from the EU-15 decreased following 1994 compared with immigrants from "Other developed regions" in the first years after the implementation of liberalization of migration within the EEA. However, the long-run effect is much weaker both by extending the post-1994 period to 2007 and investigating by lead and lag effects in our regression results. The results suggest that the effects of the EEA are largely transitory. In terms of the probability of an immigrant becoming an inventor, we initially see an increased probability, but the effect turns insignificant when we control human capital in the immigrants' region of origin. This suggests that the growing number of inventors from the EU-15 is the result of its increasing human capital, but not the result of liberalization of migration. The education results are reconcilable with the assumption that moving costs decreased more for low-skilled people as a result from free migration in EEA. 
It is difficult to generalize the impact of liberalization of migration on skill structure of immigrants in Sweden to other countries or other periods. This is because Sweden has some special features in terms of its migration policy (e.g., dominated by refugees and familyreunification movers since 1968) and economic situation (e.g., relatively high wages for lowskilled workers) compared with other countries. Nonetheless, the results indicate that for countries with a negative selection of migrants, liberalization of migration may have a negative effect on the skill structure of their new immigrants in the short-run, which they may need to prepare for. However, in the long-term, they may not need to worry too much about it.

\section{Endnotes}

${ }^{1} \mathrm{H}-1 \mathrm{~B}$ visa is a temporary work visa in the USA for highly skilled immigrants with at least a bachelor's degree (or equivalent).

${ }^{2}$ In 2016, the population was 9.9 million in Sweden and 8.6 million in Austria (Countrymeters 2016; Statistics Sweden 2017); in 2013, the proportion of foreign born was 16.0\% in Sweden and 16.7\% in Austria (OECD 2016a). In 2014, Sweden devoted 28.1\% of its gross domestic product (GDP) to social expenditures; for Austria, the corresponding figure was 28.6\% (OECD 2016b).

${ }^{3}$ For example, by the end of 2011, immigrants in Austria originated mainly in Germany, the former Yugoslavia, and Turkey (MMWD and South East Europe 2013). However, for Sweden, the countries that sent the most migrants are Finland, Iraq, Poland, and Iran (Statistics Sweden 2016). In Austria, 89\% of the foreign-born originated in European countries, while the corresponding figure in Sweden was only 49\% in 2015 (OECD 2016c; Statistics Sweden 2016).

${ }^{4}$ See the Table 6 in Appendix 1 for a country list and descriptive information of EU-15 and EEA countries.

${ }^{5}$ The Swedish government has tightened the criteria for obtaining asylum in Sweden since June 2015 because the large inflow of refugees had generated serious social and financial problems. However, even with the new restrictions in place, Sweden still attracts large numbers of refugees.

${ }^{6} \mathrm{~A}$ third situation discussed by Borjas (1987) is the case of refugee sorting, which is not relevant for the Sweden-EU situation in the period we analyze.

${ }^{7}$ We note that such adaptation or assimilation costs could be part of the story or not, depending on the length of time an immigrant spends in the destination country. Note that the opportunity cost of losing a job is already incorporated in the net benefit calculation of the model and is not part of the "costs" as such.

${ }^{8}$ The Swedish social security number is a unique identification number for each resident in Sweden, including foreigners with a valid residence permit for at least 1 year.

${ }^{9}$ Zheng and Ejermo (2015) give additional details on the match and analysis of data. Fractional count means that each co-patent is counted as a fraction, depending on how many inventors contributed to one patent. For example, if one patent has three coinventors, then each inventor is attributed one third of the patent.

${ }^{10}$ When we use "All other regions" as a control group, the effect of decreasing education level for immigrants from the EU-15 tend to be smaller and become insignificant in terms of the low and high education after the liberalization of migration in EEA; moreover, the probability of an immigrant becoming an inventor increased in the short run. 
${ }^{11}$ Table 7 shows that immigrants from the rest of Europe and the former SU have much lower employment rate compared with other groups. Graphs A and B in Fig. 2 show that the low- and middle-educated immigrants in this group increased rapidly in 1994.

${ }^{12}$ Results of robustness checks (available upon request) in which include migrants from the rest of Europe and the former SU do not change results substantially.

${ }^{13}$ The results are robust both when using data for 1985-2007 (without data on marriage or children) and 1990-2007, regardless of whether we include or exclude marriage and children. Results are available upon request.

${ }^{14}$ For example, a region has countries $\mathrm{A}$ and $\mathrm{B}$ with population sizes 4 and 5 and human capital measures of 2 and 3, respectively. The weighted measure is then $\left(4^{*} 2+5^{*} 3\right) /(4+5)$.

\section{Appendix 1}

The member countries of EEA; GDP, population, and GDP per capital in EU-15 countries in 1994

EEA countries for which the agreement had an impact on mobility to Sweden are the EU-15 countries: Austria, Belgium, France, Germany, Greece, Ireland, Italy, Luxembourg, the Netherlands, Portugal, Spain, and the UK. Normally, Sweden, Finland, and Denmark would be included, but as they are also Nordic countries, they have already had free mobility since 1954 and hence are excluded.

Table 6 Member countries of EEA at its inception and corresponding GDP, population, and GDP per capita in 1994

\begin{tabular}{|c|c|c|c|}
\hline Country & GDP in $1994(A)$ & Population in 1994 (B) & GDP/capita (C) \\
\hline \multicolumn{4}{|c|}{ Non-Nordic EEA countries } \\
\hline Austria & 141,845 & 8028 & 17,670 \\
\hline Belgium & 181,217 & 10,123 & 17,902 \\
\hline France & $1,071,856$ & 59,459 & 18,027 \\
\hline Germany & $1,374,614$ & 81,414 & 16,884 \\
\hline Greece & 105,717 & 10,430 & 10,136 \\
\hline Ireland & 47,429 & 3596 & 13,191 \\
\hline Italy & 959,866 & 57,228 & 16,773 \\
\hline Luxembourg & 10,554 & 404 & 26,145 \\
\hline Netherlands & 280,344 & 15,384 & 18,223 \\
\hline Portugal & 112,096 & 10,028 & 11,179 \\
\hline Spain & 497,471 & 39,708 & 12,528 \\
\hline UK & $1,000,281$ & 58,089 & 17,220 \\
\hline Sum & $5,783,290$ & 353,891 & - \\
\hline Weighted average & - & - & 16,342 \\
\hline \multicolumn{4}{|l|}{ Nordic EEA countries } \\
\hline Denmark & 103,317 & 5206 & 19,847 \\
\hline Finland & 78,928 & 5086 & 15,518 \\
\hline Iceland & 4651 & 266 & 17,481 \\
\hline Norway & 90,364 & 4337 & 20,837 \\
\hline Sum & 277,260 & 14,895 & - \\
\hline Weighted average & - & - & 18,614 \\
\hline Sweden & 151,582 & 8789 & 17,248 \\
\hline
\end{tabular}

Note: Total GDP, in millions of 1990 US\$ (converted at Geary Khamis PPPs). Source: Conference Board (2016) 
Table 7 Employment rates (\%) for immigrants who migrated at ages 18-64 and were employed within 2 years after they migrated to Sweden, by year of migration and region of origin

\begin{tabular}{lllllll}
\hline & $1990-1997$ & & & $1985-2007$ & \\
\cline { 2 - 3 } Region of origin & $1990-93$ & $1994-97$ & & $1985-1993$ & 1994-2007 \\
\hline EU-15 & 65.5 & 62.3 & & 63.7 & 62.7 \\
Other developed regions & 68.1 & 52.8 & & 61.6 & 58.3 \\
All other regions & 41.3 & 33.1 & & 37.9 & 43.1 \\
The rest of Europe + former SU & 32.5 & 23.0 & & 26.9 & 42.0 \\
\hline
\end{tabular}

Notes: (1) Immigrants who get employed within 2 years after migration are considered economic migrants. We use employment data on 2 years instead of 1 year after migration because the data on 1 year after migration are usually not well registered. Employment rate = No. of population in employment/Total no. of working-age (18-64) population, including both fully and partly employed. (2) Former SU = former Soviet Union. Source: Statistics Sweden

Table 8 Linear probability models for migrants aged 18-64 being low, middle, or highly educated at the time of migration (no imputation on education data), 1990-1997 vs. 1990-2007

\begin{tabular}{|c|c|c|c|c|c|c|}
\hline & \multicolumn{3}{|l|}{ 1990-1997 } & \multicolumn{3}{|l|}{ 1990-2007 } \\
\hline & 1.1 & 1.2 & 1.3 & 2.1 & 2.2 & 2.3 \\
\hline & Low2_97 & Mid2_97 & High2_97 & Low2_07 & Mid2_07 & High2_07 \\
\hline \multirow[t]{2}{*}{ EU-15 × 1994-1997 } & -0.006 & $0.099^{* * *}$ & $-0.093^{* * *}$ & -0.006 & $0.041^{* * *}$ & $-0.036^{* * *}$ \\
\hline & $(0.022)$ & $(0.028)$ & $(0.028)$ & $(0.012)$ & $(0.014)$ & $(0.013)$ \\
\hline \multirow[t]{2}{*}{ Age of migration } & $-0.045^{* * *}$ & $-0.033^{* * *}$ & $0.078^{* * *}$ & $-0.030^{* * *}$ & $-0.040^{* * *}$ & $0.070^{* * *}$ \\
\hline & $(0.003)$ & $(0.003)$ & $(0.002)$ & $(0.001)$ & $(0.001)$ & $(0.001)$ \\
\hline \multirow[t]{2}{*}{$\mathrm{Age}^{2}$ of migration } & $0.001^{* * *}$ & $0.000^{* * *}$ & $-0.001^{* * *}$ & $0.000^{* * *}$ & $0.001^{* * *}$ & $-0.001^{* * *}$ \\
\hline & $(0.000)$ & $(0.000)$ & $(0.000)$ & $(0.000)$ & $(0.000)$ & $(0.000)$ \\
\hline \multirow[t]{2}{*}{ Gender (omit: male) } & $-0.041^{* * *}$ & -0.004 & $0.045^{* * *}$ & $-0.027^{* * *}$ & $-0.023^{* * *}$ & $0.050^{* * *}$ \\
\hline & $(0.006)$ & $(0.007)$ & $(0.007)$ & $(0.002)$ & $(0.004)$ & $(0.004)$ \\
\hline \multirow[t]{2}{*}{ Marriage } & $-0.019^{* *}$ & 0.000 & $0.018^{* *}$ & $-0.018^{* * *}$ & $0.017^{* * *}$ & 0.001 \\
\hline & $(0.008)$ & $(0.009)$ & $(0.009)$ & $(0.003)$ & $(0.004)$ & $(0.005)$ \\
\hline \multirow[t]{2}{*}{ Children } & $0.119^{* * *}$ & $-0.017^{*}$ & $-0.101^{* * *}$ & $0.058^{* * *}$ & $0.013^{* * *}$ & $-0.072^{* * *}$ \\
\hline & $(0.009)$ & $(0.009)$ & $(0.009)$ & $(0.004)$ & $(0.005)$ & $(0.005)$ \\
\hline \multirow[t]{2}{*}{ Human capital } & -0.496 & $-2.976^{* *}$ & $3.472^{* *}$ & $-0.416^{* * *}$ & $-0.195^{*}$ & $0.611^{* * *}$ \\
\hline & $(0.958)$ & (1.374) & $(1.386)$ & $(0.075)$ & $(0.115)$ & $(0.121)$ \\
\hline Year of immigration FE & Yes & Yes & Yes & Yes & Yes & Yes \\
\hline Region of origin FE & Yes & Yes & Yes & Yes & Yes & Yes \\
\hline Observations & 15,614 & 15,614 & 15,614 & 56,366 & 56,366 & 56,366 \\
\hline Adjusted $R^{2}$ & 0.289 & 0.425 & 0.562 & 0.204 & 0.305 & 0.722 \\
\hline
\end{tabular}

Robust standard errors in parentheses. Source: Statistics Sweden ${ }^{* * *} p<0.01 ;{ }^{* *} p<0.05 ;{ }^{*} p<0.1$ 
Table 9 Ordinary least square (OLS) regressions of the probability of a migrant being low, middle, or highly educated at the time of migration and becoming an inventor from the time of migration until 2007, 1990-2007 vs. 1985-2007

\begin{tabular}{|c|c|c|c|c|c|c|c|c|}
\hline & \multicolumn{8}{|c|}{ Control: Other developed regions } \\
\hline & \multicolumn{4}{|l|}{$1990-2007$} & \multicolumn{4}{|l|}{$1985-2007$} \\
\hline & 1.1 & 1.2 & 1.3 & 1.4 & 2.1 & 2.2 & 2.3 & 2.4 \\
\hline & 90_Low2 & 90_Mid2 & 90_High2 & 90_Pat2 & 85_Low2 & 85_Mid2 & 85_High2 & 85_Pat2 \\
\hline \multirow[t]{2}{*}{ EU-15 × 1994-2007 } & $0.014^{* *}$ & 0.012 & $-0.026^{* * *}$ & -0.001 & $0.013^{* *}$ & 0.004 & $-0.017^{* * *}$ & -0.000 \\
\hline & $(0.007)$ & $(0.009)$ & $(0.009)$ & $(0.001)$ & $(0.005)$ & $(0.007)$ & $(0.006)$ & $(0.001)$ \\
\hline \multirow[t]{2}{*}{ Age at migration } & $-0.024^{* * *}$ & $-0.055^{* * *}$ & $0.079^{* * *}$ & $0.001^{* * *}$ & $-0.025^{* * *}$ & $-0.048^{* * *}$ & $0.073^{* * *}$ & $0.001^{* * *}$ \\
\hline & $(0.001)$ & $(0.001)$ & $(0.001)$ & $(0.000)$ & $(0.001)$ & $(0.001)$ & $(0.001)$ & $(0.000)$ \\
\hline \multirow[t]{2}{*}{ Age $^{2}$ at migration } & $0.000^{* * *}$ & $0.001^{* * *}$ & $-0.001^{* * *}$ & $-0.000^{* * *}$ & $0.000^{* * *}$ & $0.001^{* * *}$ & $-0.001^{* * *}$ & $-0.000^{* * *}$ \\
\hline & $(0.000)$ & $(0.000)$ & $(0.000)$ & $(0.000)$ & $(0.000)$ & $(0.000)$ & $(0.000)$ & $(0.000)$ \\
\hline \multirow[t]{2}{*}{ Female } & $-0.025^{* * *}$ & $0.008^{* * *}$ & $0.017^{* * *}$ & $-0.004^{* * *}$ & $-0.026^{* * *}$ & $0.010^{* * *}$ & $0.016^{* * *}$ & $-0.004^{* * *}$ \\
\hline & $(0.002)$ & $(0.003)$ & $(0.003)$ & $(0.000)$ & $(0.002)$ & $(0.003)$ & $(0.003)$ & $(0.000)$ \\
\hline \multirow[t]{2}{*}{ Human capital } & $-0.318^{* * *}$ & $-0.347^{* * *}$ & $0.665^{* * *}$ & 0.020 & $-0.390^{* * *}$ & $-0.298^{* * *}$ & $0.689^{* * *}$ & $0.015^{*}$ \\
\hline & $(0.056)$ & $(0.096)$ & $(0.100)$ & $(0.012)$ & $(0.056)$ & $(0.083)$ & $(0.084)$ & $(0.009)$ \\
\hline Year of immigration FE & Yes & Yes & Yes & Yes & Yes & Yes & Yes & Yes \\
\hline Region of origin FE & Yes & Yes & Yes & Yes & Yes & Yes & Yes & Yes \\
\hline Observations & 103,516 & 103,516 & 103,516 & 103,516 & 128,474 & 128,474 & 128,474 & 128,474 \\
\hline Adjusted $R^{2}$ & 0.167 & 0.364 & 0.640 & 0.006 & 0.237 & 0.396 & 0.611 & 0.006 \\
\hline
\end{tabular}

Robust standard errors in parentheses. Source: Statistics Sweden and CIRCLE data on inventors ${ }^{* * *} p<0.01 ;{ }^{* *} p<0.05 ;{ }^{*} p<0.1$

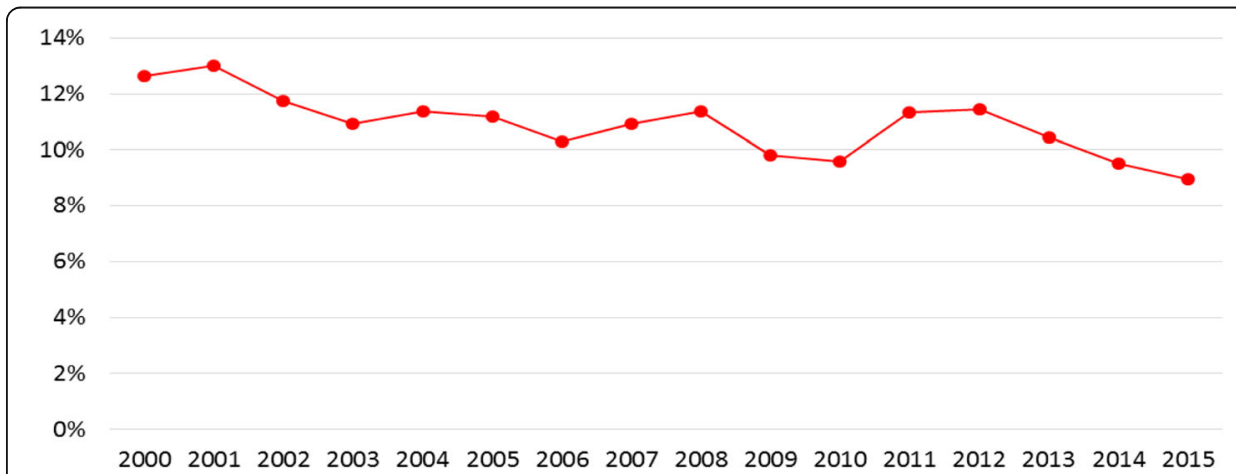

Fig. 4 Percentage of immigrants from the EU-15 as a share of all immigrants to Sweden, 2000-2015. Source: Statistics Sweden 


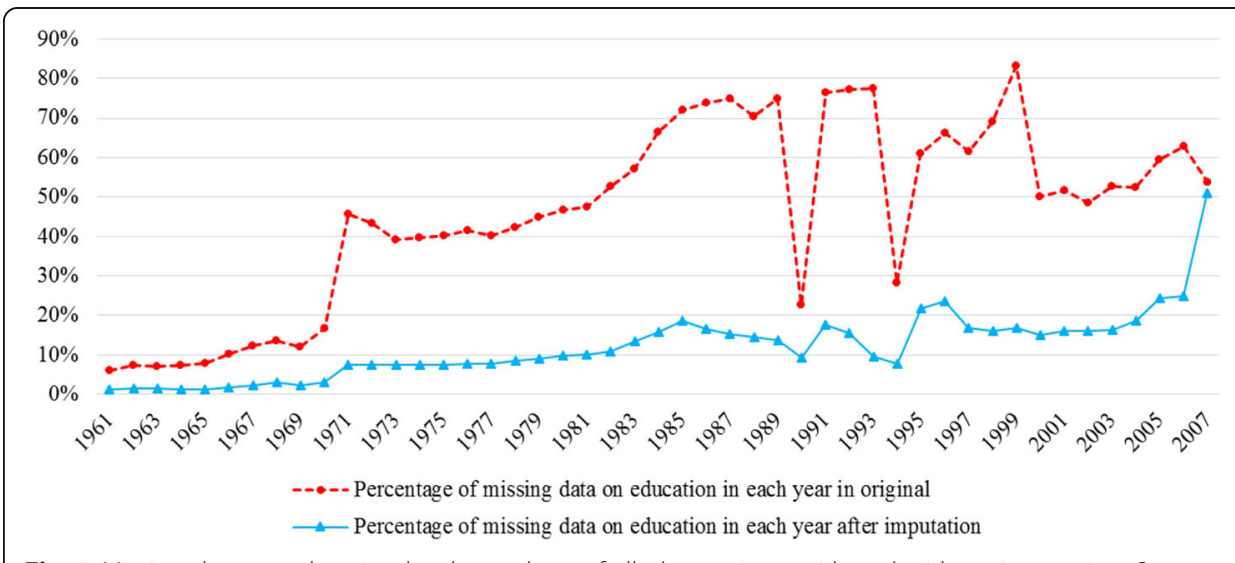

Fig. 5 Missing data on education level as a share of all observations, with and without imputation. Source: Statistics Sweden

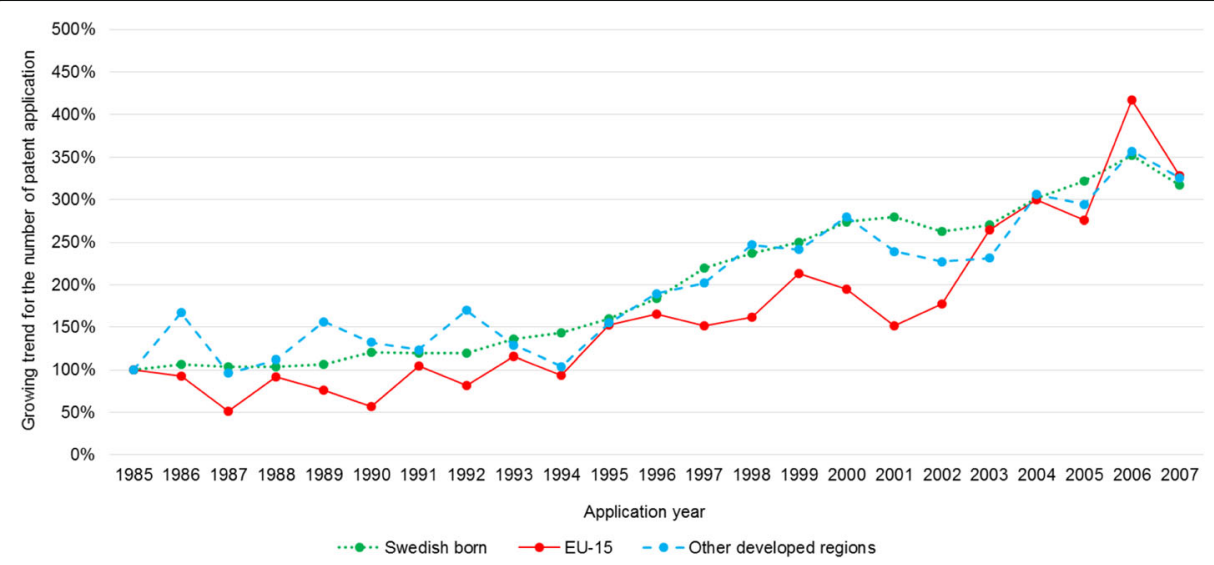

Fig. 6 Growing trend for the number of patent applications by Swedish born, EU-15 immigrants, and immigrants from "Other developed regions," 1985-2007. Index $1985=100$. Source: Statistics Sweden and CIRCLE data on inventors 


\section{Appendix 2}

\section{The Grogger-Hanson model with skill-differentiated fixed costs}

The original model distinguishes between low-skilled $(L)$ and highly skilled $(H)$ workers, where wages $(w)$ are specified as

$$
\begin{aligned}
& \ln w_{k}^{L}=\mu_{k}, \\
& \ln w_{k}^{H}=\mu_{k}+\delta_{k},
\end{aligned}
$$

where $\mu_{k}$ is a constant and $\delta_{k}$ is the wage premium associated with high skills in country $k$ ("Sweden"). $L$ means low-skilled and $H$ means high-skilled. The fixed cost of moving from home country 0 (i.e., "the EU-15") to $k$ is $C_{0 k}$. In the model, utility is linearly and positively dependent on net income, such that for skill level $j=L, H$ :

$$
U_{i 0 k}^{j}=\alpha\left(w_{k}^{j}-C_{0 k}\right)+\varepsilon_{i 0 k}^{j}
$$

Assuming that the error terms $\varepsilon_{i 0 k}^{j}$ are independent and identically distributed (i.i.d.) with an extreme value distribution, the (natural) log odds ratio of choosing country $k$ over 0, following McFadden (1974), is

$$
\ln \frac{p_{0 k}^{j}}{1-p_{0 k}^{j}}=\alpha\left(w_{k}^{j}-w_{0}^{j}\right)-\alpha C_{0 k} .
$$

The selection pattern is obtained as the difference in log odds ratios of Eq. (6) among skill groups:

$$
\ln \frac{p_{0 k}^{H}}{1-p_{0 k}^{H}}-\ln \frac{p_{0 k}^{L}}{1-p_{0 k}^{L}}=\alpha\left[\left(w_{k}^{H}-w_{0}^{H}\right)-\left(w_{k}^{L}-w_{0}^{L}\right)\right]
$$

In Eq. (7), fixed costs are eliminated. This means that positive selection takes place if the absolute wage premium difference is positive. If average wages are the same, there is positive selection if $\delta_{k}>\delta_{0}$, but Eq. (7) can still imply positive selection even if $\delta_{k} \leq \delta_{0}$ if $\mu_{k}$ is much larger than $\mu_{0}$.

The effects of the EEA should be understood as increasing the possibility of going to Sweden without visa requirements, which thus lowers the cost of moving. Obtaining a visa was presumably easier ("low cost") for highly skilled people than low-skilled ones who wanted to go to Sweden. This makes the Swedish case different from that of Austria, as Austria had "low costs" in its attraction of low-skilled workers from the EU-15 before the accession to the EEA (Huber and Bock-Schappelwein 2014). If we modify the Grogger and Hanson (2011) model to allow the fixed cost to vary, we can rewrite Eq. (5) to

$$
\bar{U}_{i 0 k}^{j}=\alpha\left(\bar{w}_{k}^{j}-\bar{C}_{0 k}^{j}\right)+\bar{\varepsilon}_{i 0 k}^{j},
$$

So that fixed costs differ by $j$, denoted $\bar{C}_{0 k}^{j}$. We use a bar above variables to denote the pre-EEA situation and let the previously defined equations describe the post-EEA situation. We assume that $\bar{C}_{0 k}^{L}>\bar{C}_{0 k}^{H}$. Furthermore, Eq. (7) is modified as 


$$
\operatorname{In} \frac{\bar{p}_{0 k}^{H}}{1-\bar{p}_{0 k}^{H}}-\operatorname{In} \frac{\bar{p}_{0 k}^{L}}{1-\bar{p}_{0 k}^{L}}=\alpha\left[\left(\bar{w}_{k}^{H}-\bar{w}_{0}^{H}-\bar{C}_{0 k}^{H}\right)-\left(\bar{w}_{k}^{l}-\bar{w}_{0}^{L}-\bar{C}_{0 k}^{L}\right)\right] .
$$

Taking the difference between Eqs. (7) and (9) shows the change in selection patterns:

$$
\begin{aligned}
& \alpha\left[\left(w_{k}^{H}-w_{0}^{H}\right)-\left(w_{k}^{L}-w_{0}^{L}\right)\right]-\alpha\left[\left(\bar{w}_{k}^{H}-\bar{w}_{0}^{H}-\bar{C}_{0 k}^{H}\right)-\left(\bar{w}_{k}^{L}-\bar{w}_{0}^{L}-\bar{C}_{0 k}^{L}\right)\right] \\
& \quad=\alpha\left[\Delta W_{0 k}^{H}-\Delta W_{0 k}^{L}+\left(\bar{C}_{0 k}^{H}-\bar{C}_{0 k}^{L}\right)\right],
\end{aligned}
$$

where $\Delta W_{0 k}^{j}$ is the change in the wage differential for $j$-skilled workers following the reform and in comparison to the EU-15. The change in selection is (more) positive if the wage differential for highly skilled workers becomes more pronounced in the destination country after the EEA was introduced and if the returns to low-skilled workers decreased in the destination country relative to the home country. Although marginal taxes in Sweden fell in the early 1990s, they have risen somewhat since, such that Sweden has one of the highest marginal tax rates in the world (KPMG 2012). Moreover, World Bank data on Gini coefficients do not suggest that trends in Sweden with respect to income distribution changed substantially during the period 1990-2000 (Milanovic 2013). This means that it is hard to argue that net wages for highly skilled workers $\left(\Delta W_{0 k}^{H}\right)$ have generally increased for those who go to Sweden compared to other countries in the EEA. Therefore, $\Delta W_{0 k}^{H}-\Delta W_{0 k}^{L}$ has probably either gone down or is close to 0 . That means that pre-EEA moving costs are critical to the results. Since we have argued that $\left(\bar{C}_{0 k}^{H}-\bar{C}_{0 k}^{L}\right)<0$, this suggests a more negative selection change following the EEA.

Based on these arguments, we expect that the average skill level among immigrants from the EU-15 to Sweden declined after 1994, when Sweden became a member of the EEA.

\section{Acknowledgements}

We would like to thank the anonymous referee and the editor for the very helpful comments which helped improve the paper. We are also grateful to comments and suggestions for this paper in seminars at CIRCLE and the Department of Economic History, Lund University. The views presented in this paper are solely those of the authors. Responsible editor: Jackline Wahba

Funding

There is no funding source that needs to be acknowledged for this paper.

\section{Competing interests}

The IZA Journal of Development and Migration is committed to the IZA Guiding Principles of Research Integrity. The authors declare that they have observed these principles.

\section{Publisher's Note}

Springer Nature remains neutral with regard to jurisdictional claims in published maps and institutional affiliations.

Received: 17 March 2017 Accepted: 25 September 2017

Published online: 08 March 2018

References

Angrist J, Pischke JS. Mostly harmless econometrics: an empiricists guide. Princeton: Princeton University Press; 2009.

Azoulay P, Ding W, Stuart T. The determinants of faculty patenting behavior: demographics or opportunities? J Econ Behav Organ. 2007;63:599-623.

Beerli A, Indergand R. Which factors drive the skill-mix of migrants in the long-run? Zurich: Working Paper Series. University of Zurich, Department of Economics; 2014.

Bevelander P. Immigrant employment integration and structural change in Sweden, 1970-1995. Dissertation, Media-Tryck, Lund University; 2000.

Bianchi M. Immigration policy and self-selecting migrants. JPET. 2013;15(1):1-23.

Borjas GJ. Self-selection and the earnings of immigrants. Am Econ Rev. 1987;77:531-53. 
Borjas GJ. The intergenerational mobility of immigrants. J Labor Econ. 1993;11(1):113-35.

Cerna L. Changes in Swedish labour immigration policy: a slight revolution? SULCIS Working Paper. Stockholm University Linnaeus Center for Integration Studies - SULCIS; 2009.

Chen YP. Skill-sorting, self-selectivity, and immigration policy regime change: two surveys of Chinese graduate students' intention to study abroad. Am Econ Rev. 2005;95(2):66-70.

Countrymeters (2016) Austria population clock. Available from: http://countrymeters.info/en/Austrial. Accessed 3 Oct 2016.

Ding WW, Murray F, Stuart TE. Gender differences in patenting in the academic life sciences. Science. 2006;313(5787):665-7.

Djajic S. Skills and the pattern of migration: the role of qualitative and quantitative restrictions on international labor mobility. I ER. 1989;30(4):795-809.

Dustmann C, Frattini T, Rosso A. The effect of emigration from Poland on Polish wages. Scand J Econ. 2015;117(2):522-64.

Elsner B. Does emigration benefit the stayers? Evidence from EU enlargement. J Pop Econ. 2013a;26(2):531-53.

Elsner B. Emigration and wages: the EU enlargement experiment. J Int Econ. 2013b;91(1):154-63.

Feenstra RC, Inklaar R, Timmer MP. The next generation of the Penn World Table. Am Econ Rev. 2015;105(10):3150-82.

Forskarskattenämnden. (2013) Tax relief for foreign key personnel. Forskarskattenämnden. Available from:

http://skatterattsnamnden.se/forskarskattenamnden/summaryinenglish/taxreliefforforeignkeypersonnel.4. 383cc9f31134f01c98a800018147.html.

Gerdes C, Wadensjö E. Immigrants from the new member states and the Swedish welfare state. SIEPS Report. 2008;9:1-24.

Giordani PE, and Ruta M (2010). Prejudice and immigration. Working paper.

Granger CW. Investigating causal relations by econometric models and cross-spectral methods: Econometrica: J Econometric Soc; 1969;37(3):424-38.

Grogger J, Hanson GH. Income maximization and the selection and sorting of international migrants. J Dev Econ. 2011; 95(1):42-57.

Helgertz J. Immigrant careers—-why country of origin matters: Dissertation. Lund; Media-Tryck, Lund University; 2010.

Huber P, Bock-Schappelwein J. The effects of liberalizing migration on permanent migrants' education structure. J Common Mark Stud. 2014;52(2):268-84.

Jahn V, Steinhardt MF. Innovation and immigration-insights from a placement policy. Econ Lett. 2016;146(C):116-9.

Jung T, Ejermo O. Demographic patterns and trends in patenting: gender, age, and education of inventors. Technol Forecast Soc Change. 2014;86:110-24.

Kato T, Sparber C. Quotas and quality: the effect of $\mathrm{H}-1 \mathrm{~B}$ visa restrictions on the pool of prospective undergraduate students from abroad. Rev Econ Stat. 2013;95(1):109-26.

Kerr WR, Lincoln WF. The supply side of innovation: H-1B visa reforms and US ethnic invention. J Labor Econ. 2010; 28(3):473-508.

KPMG (2012) KPMG's individual income tax and social security rate survey 2012. KPMG International Cooperative. Available from: https://assets.kpmg.com/content/dam/kpmg/pdf/2012/10/RPF-2012.pdf. Accessed 9 May 2014.

Mahroum S. Europe and the immigration of highly skilled labour. Int Migr. 2001;39(5):27-43.

Mayda AM. International migration: a panel data analysis of the determinants of bilateral flows. J Pop Econ. 2010;23(4):1249-74.

McFadden D. The measurement of urban travel demand. J Public Econ. 1974:3(4):303-28.

McKenzie D, Rapoport H. Self-selection patterns in Mexico-US migration: the role of migration networks. Rev Econ Stat. 2010;92(4):811-21.

MMWD and South East Europe. Migration profile of Austria. South East Europe: Programme; 2013.

Milanovic BL (2013) All the Ginis Dataset. The World Bank. Available from: https://data.worldbank.org/data-catalog/allthe-ginis. Accessed 31 Mar 2017.

OECD (2016a) Foreign-born population. OECD. Available from: https://data.oecd.org/migration/foreign-born-population. htm. Accessed 3 Oct 2016

OECD (2016b) Social expenditure—aggregated data. Available from: http://stats.oecd.org/Index.aspx?\%20DataSetCode= SOCX_AGG. Accessed 4 Oct 2016.

OECD (2016c) Immigrants by citizenship and age. OECD. Available from: http://stats.oecd.org. Accessed 4 Oct 2016.

Ruhs M. Is unrestricted immigration compatible with inclusive welfare states? National Institutions: Citizenship Norms and the Politics of Free Movement in the European Union; 2016. Available from: https:/papers.ssrn.com/sol3/ papers.cfm?abstract_id=2625486.

Stalker P. Migration trends and migration policy in Europe. Int Migr. 2002;40(5):151-79.

Statistics Sweden (2016) Immigrations and emigrations by country of birth and sex. Year 2000-2015. Statistics Sweden. Available from: http://www.statistikdatabasen.scb.se/pxweb/en/ssd/START_BE_BE0101_BE0101J//mmiEmiFod/ ? rxid=81923a90-4a9b-4640-8636-19c3b67fd2ba. Accessed 29 Aug 2016.

Statistics Sweden (2017) Population 1 November by region, age and sex. Year, 2002-2016. Available from: http://uww. statistikdatabasen.scb.se/pxweb/en/ssd/START_BE_BE0101__BE0101A/FolkmangdNov/?rxid=81923a90-4a9b-46408636-19c3b67fd2ba. Accessed 10 Oct 2017.

Sweden S. Befolkningsförändringar 1988. Stockholm: Statistics Sweden; 1989. p. p172-3.

Sweden S. Befolkningsförändringar 1989. Stockholm: Statistics Sweden; 1990. p. p174-5.

Sweden S. Befolkningsförändringar 1990. Stockholm: Statistics Sweden; 1991. p. p148-9.

Westin C (2000) The effectiveness of settlement and integration policies towards immigrants and their descendants in Sweden. Available from: http://www.oit.org/wcmsp5/groups/public/—ed_protect/—protrav/_-migrant/documents/ publication/wcms_201879.pdf. Accessed 10 Oct 2014.

Zheng Y, Ejermo O. How do the non-native perform in inventive activity? Evidence from Sweden. J Pop Econ. 2015; 28(3):659-95. 